\title{
Necrològica
}

Collectanea Botanica

vol. 31 (2012): 127-128

ISSN: 0010-0730

doi: 10.3989/collectbot.2012.v31.012

\section{Jaume Josa i Llorca (1945-2012)}

\author{
A. SUSANNA \\ Institut Botànic de Barcelona (IBB-CSIC-ICUB), pg. del Migdia, s/n, ES-08038 Barcelona, España \\ E-mail: asusanna@ibb.csic.es
}

El Institut Botànic de Barcelona acaba de perder a uno de sus mejores valedores; y el que firma esta nota ha perdido a un gran amigo. Jaume Josa, Coordinador Institucional de CSIC en Catalunya entre 1996 y 2000, fue el principal impulsor de la firma, en 1998, del nuevo convenio de colaboración entre el CSIC y el Ajuntament de Barcelona que supuso el principio de una de las etapas más felices del centro; y supo transmitir su entusiasmo por el Institut Botànic a su sucesor al frente del CSIC en Catalunya, Lluís Calvo.

Hijo de maestros represaliados por el franquismo, estudió biología en la Universidad de Barcelona, estudios que interrumpió a raíz de su participación en la «Caputxinada» [Sobre su detención por la Brigada Político-Social se conserva el acta de la policía, con su declaración tan delirante como divertida, que uno de sus amigos nos leyó en su funeral. Uno tan propio de Jaume Josa como uno pudiera imaginar: una misa corpore insepulto cantada en latín por un cura (por supuesto, amigo suyo) con aire de ermitaño antiguo, ante una parroquia formada en su mayoría por ateos furibundos - algo que sólo él hubiera sido capaz de lograr - y con parlamentos de amigos del pueblo soberano, de compañeros del mundo científico y de taurófilos. Y sin siquiera estar presente: en una última demostración de carácter, legó su cuerpo a la ciencia]. Jaume estudió entonces magisterio y más adelante terminó sus estudios de biología, especializándose en historia de la ciencia. En esta disciplina, que enseñó en la Universidad de Barcelona durante muchos años, era el máximo especialista en España sobre la obra de Charles Darwin. Amplió sus estudios en Inglaterra, de donde adquirió un cierto dandismo indumentario y un fino humor anglosajón que combinaba magistralmente con la sal gorda del humor levantino de su tierra.

Fue un hombre de una gran agudeza, sardónico, que miraba el mundo con el distanciamiento de un intelectual de otros tiempos: culto, formidable orador, amenísimo conversador. Su cultura, tan enciclopédica como sorprendente, se extendía a ámbitos tan insólitos como la historia de la tauromaquia medieval en Catalunya, las peculiaridades del comportamiento de las mulas del ejército español

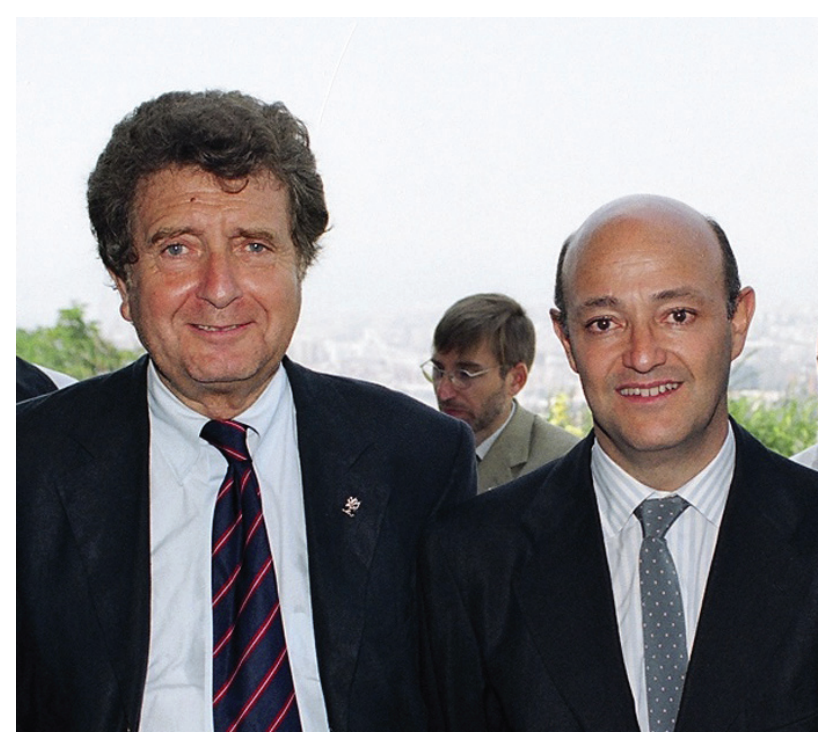

Jaume Josa y Alfonso Susanna en julio de 2003, en el acto de inauguración de la nueva sede del Institut Botànic de Barcelona. 
o la obra pictórica y poética de Joan Brossa, cuya amistad cultivó (junto con las otras amistades tan improbables como verídicas entre el mundo de la farándula barcelonesa).

Jaume Josa, al pasar revista a su vida con uno de sus amigos poco antes de dejarnos, confesó que tenía tres grandes motivos de orgullo en una vida plena y rica: su labor al frente del Servicio de Publicaciones del CSIC, que revolucionó entre 1984 y 1989; su obra monumental sobre Darwin, publicada en 2007 con Alberto Gomis; y... nuestro Institut Botànic de Barcelona; un recuerdo de cariño que sigue emocionando a los que compartimos su pasión por la historia de nuestro centro.

Con la misma generosidad con la que se entregaba a cualquiera de sus causas, sea la defensa del Institut Botànic en 1998 o la del mundo taurino al final de su vida, Jaume Josa no quiso preocupar a sus amigos y no nos dijo una pala- bra de su enfermedad: en el Institut Botànic le creíamos algo apagado y echábamos en falta sus habituales bromas epistolares, pero no sabíamos que estuviera enfermo. Lo sentimos de verdad, porque, aunque a él no le hubiera hecho ninguna gracia, a nosotros nos hubiera gustado al menos darle un abrazo.

Debajo de sus maneras y de su imagen, personalísimas y cuidadosamente cultivadas, había una persona firme, insobornable, sólida, generosa de sí misma; y un entrañable amigo de sus amigos. El Institut Botànic de Barcelona es hoy un poco más pobre y más triste. Esperábamos que nuestra sala de eméritos, sobre cuya creación él insistió tanto, se viera alegrada muy a menudo por su presencia en el momento en el que se jubilara. En su honor, terminemos esta nota como siempre le gustaba terminar nuestras conversaciones: con su grito personalísimo Visca la Botànica! 